\title{
Locusts on the march again
}

Locust swarms are spreading in the Horn of Africa and the Arabian peninsula. Chris Sherwell reports.

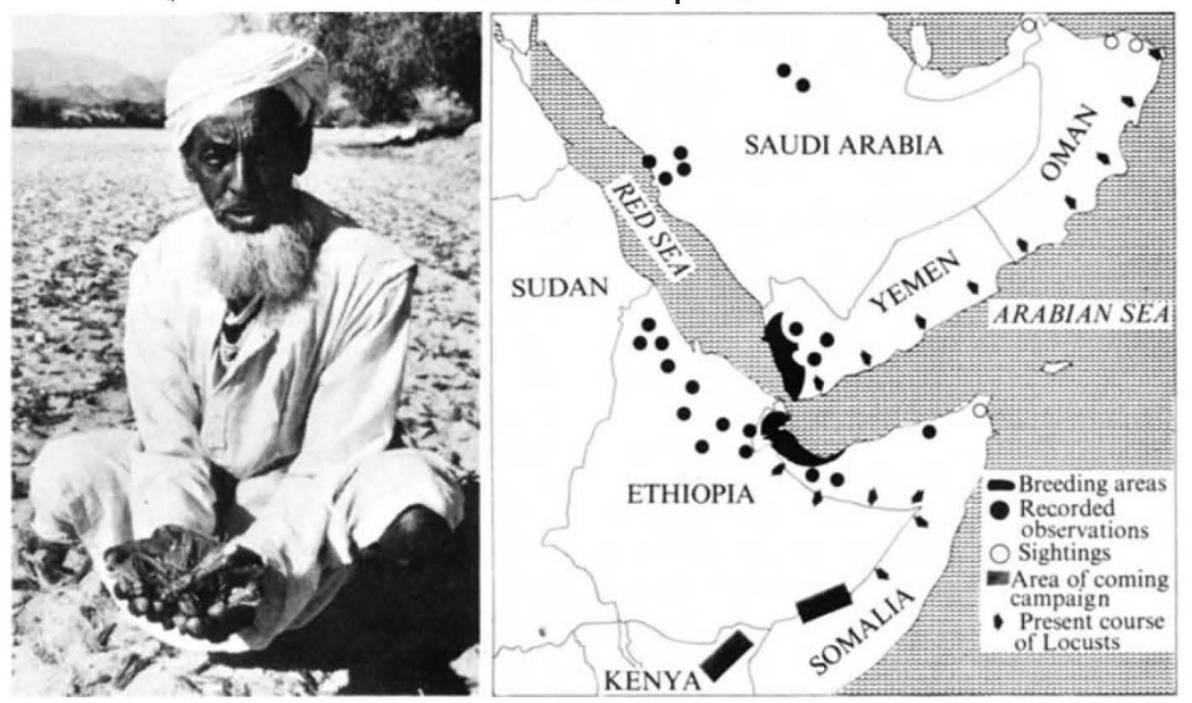

A locust scout in Ethiopia (left) counting the number of dead locusts in a given area after aerial spraying. Sixteen years after the last major locust plague, surveying has become less rigorous and so less effective. Now that locusts are breeding rapidly and spreading some local organisations are not fully prepared.

DESPITE hopes only a month or two ago that the locusts were receding, the world's first serious desert locust plague in 15 years is now a real threat. Swarms have been building up in the Horn of Africa and the Arabian peninsula. The insects have managed to evade hamstrung efforts to confine them to the area and are now spreading south and east, endangering the food and livelihood of millions of people. New plans are being laid to combat the threat but millions of dollars' worth of assistance is needed.

Only last week a panel of locust experts advising the UN Food and Agriculture Organisation warned of the need for emergency action over the next three months, saying $\$ 3$ millionworth of assistance "must be provided immediately". Scientists at London's Centre for Overseas Pest Research (COPR) are closely involved in monitoring the locusts' progress and believe present conditions are similar to those prevailing immediately before the outbreak of the last serious plague in 1949 That lasted until 1963.

Good rains in the Sahel and at the eastern end of the Arabian peninsula in the middle of last year seem to be the underlying cause of the problem. The rains boosted the number of locusts which appeared later in October and November in the Red Sea and Gulf of Aden area. Further widespread and prolonged rainfall encouraged more breeding (the locusts' eggs need to take up free water in the soil in order to develop) and it soon became apparent that, without control measures, an un- usually large number of locusts would be threatening the whole area this year.

Though both the Sudan and Saudi Arabia managed to take some steps, control efforts were hindered elsewhere by military engagements. War between Ethiopia and Somalia impeded ground control teams and severely limited aerial spraying operations in important locations during the early part of this year-a crucial period. Persistent outbreaks of hostilities since then (most recently in the past week), and instability in both North and South Yemen, have not lessened the difficulties. The long-running Eritrean conflict has complicated the problem further.

Reports from the area received in London last week indicate that one swarm in north-western Somalia covers some 400 to $500 \mathrm{sq} \mathrm{km}$, another covers $360 \mathrm{sq} \mathrm{km}$, and that together with about a dozen other swarms the total area infested by locusts in Somalia is about $1,600 \mathrm{sq} \mathrm{km}$. Reports from Ethiopia have put the number of swarms there at 50, some of them well over $100 \mathrm{sq} \mathrm{km}$, and though some spraying is being done the effort is thought to be too little, too late.

The damage the locusts are doing is enormous. This most-studied of insects -its activity has been documented for over 4,000 years-needs to eat its own weight each day ( 2 to 3 grams) of fresh food. A swarm covering $1 \mathrm{sq} \mathrm{km}$ might contain 40 million to 80 million locusts. This means hundreds of thousands of tonnes of vegetation are being devoured each day.

Further south in Somalia, and in
Kenya and Uganda, important cash crops such as bananas, tea and coffee could be affected, as well as staples like maize. Locusts' flying activity is affected by temperature, and under the cool conditions of the East African Highlands where such crops are prolific, the swarms would settle for days, causing particularly expensive damage.

Though the techniques of surveying have improved, an additional problem this year has been that, even allowing for difficulties of access, surveying and monitoring by local organisations has been less effective than in the past. This is partly because the period of "recession" over the past 15 years -the only interruption being a short-lived "plague" in 1968-has allowed local organisations to wind down.

Most of the responsibility for locust control over this period has thus passed upwards onto the shoulders of the Desert Locust Control Organisation of Eastern Africa (DLCOEA), an international grouping of seven countriesEthiopia, Somalia, Kenya, Tanzania, Djibouti, Uganda and Sudan. This has its headquarters in Addis Ababa and an aircraft base in Nairobi, but it has only seven aircraft, two of which are Norman-Britten Islanders from Britain which are still not ready to spray locust swarms. The rest are old Beavers. The DLCOEA is acquiring two more Islanders and specially-equipped Land Rovers, all from Britain, but the FAO panel said in its statement last week that additional assistance was needed in the form of insecticide, camping equipment, light and heavy vehicles, sprayers and light spraying planes.

How far this can help before the annual locust cycie starts repeating itself is unclear, but urgent action is certainly needed. Swarms have been sighted as far east as Gujarat state in India, in Pakistan, in the Arabian Sea and all along the Arabian peninsula coast. Fears are also growing of a westerly movement into the Sudan, Chad and the Central African Empire, perhaps threatening countries as far west as Morocco.

The DLCOEA, with help from the COPR and the FAO, is focusing its efforts on the locust swarms now breaking out of the northern part of the Horn around Djibouti and heading south carried on the prevailing winds. It is this development over the past fortnight which has caused the worries to mount, for the locusts will continue moving until they find more rain where they can breed. The experts are planning their next campaign for the Ogaden in October, provided hostilities do not break out there as well. If this fails, another campaign is already being prepared for northern Kenya. In 1954 , the locusts moved as far south as Tanzania. 